Володимир Іванович Мірненко (доктор техн. наук, професор)

Анатолій Григорович Салій (канд. військ. наук, доцент)

Петро Михайлович Яблонський (канд. техн. наук, доцент)

Микола Пилипович Бутенко

Національний університет оборони Украӥни імені Івана Черняховського, Київ, Украӥна

\title{
ТЕХНІКО-ЕКОНОМІЧНА ЕФЕКТИВНІСТЬ ЕКСПЛУАТАЦІї ЗА СТАНОМ ВИРОБІВ АВІАЦІЙНОЇ ТЕХНІКИ ДЛЯ ДИФУЗІЙНО-МОНОТОННОГО РОЗПОДІЛУ ЇХ ВІДМОВ
}

У статті представлена методика оцінки техніко-економічної ефективності експлуатаціі авіаційної техніки за станом з використанням дифузійно-монотонного розподілу ї̈ відмов з врахуванням помилок першого $i$ другого роду. Для типових умов експлуатації показані графіки залежності коефіцієнта технічного використання і питомих витрат на годину роботи виробу авіаційної техніки у справному стані від основних параметрів. Опис процесів експлуатації за станом виробів авіаційної техніки здійснюється за допомогою напівмарковського випадкового процесу, який, на відміну від марковського процесу, дозволяє більш адекватно описати експлуатаџію виробів авіаційної техніки.

Ключові слова: техніко-економічна ефективність експлуатації, коефіцієнт технічного використання, дифузійно-монотонний розподіл.

Постановка проблеми Під час експлуатації авіаційної техніки (АТ) важливо знати не тільки коефіцієнт іiі технічного використання $\left(\mathrm{K}_{\mathrm{TB}}\right)$ або коефіцієнт готовності $\left(\mathrm{K}_{\Gamma}\right)$, але й питомі витрати на годину експлуатації АТ, а також питомі витрати на годину перебування іiі у справному стані. Математична модель, що покладена у основу розрахунку технікоекономічної ефективності, докладно викладена у роботі [1]. Кожен перехід у такій моделі пов'язаний $з$ певними матеріальними витратами.

Аналіз останніх досліджень і публікацій. Відомо [2], що для високонадійних елементів 3 інтенсивністю відмов $\lambda=10^{-7} \ldots 10^{-9} \quad 1 /$ год експоненціальний закон розподілу дає суттєво завищені значення напрацювання на відмову. Так у роботі [3] вказано, що при використанні експоненціального закону математичне очікування часу до відмови (або на відмову) для високонадійних елементів приблизно у 50..500 разів перебільшує аналогічні показники для двопараметричних законів, більш адекватних до статистики відмов. Таким чином, прийняття експоненціальної моделі відмов може призвести до суттєвих помилок при створенні зразків, наприклад, авіаційної техніки.

Враховуючи це метою статті $є$ розробка методики техніко-економічної оцінки ефективності експлуатації виробів АТ за станом для моделі дифузійно-монотонного закону розподілу часу їх відмов при врахуванні помилок першого і другого роду. При цьому математична модель експлуатації описується напівмарковським процесом, який вважається більш потужним математичним методом, ніж марковський процес.
Помилки першого роду виникають на переході зі стану 1 до стану 6, а помилки другого роду виникають на переході зі стану 5 до стану 7 моделі, яка викладена у роботі [1] .

Методи дослідження. Дифузійно-монотонний закон розподілу вважається одним 3 найбільш універсальних для вирішення практично всіх задач теорії надійності [2, 3, 4]. Єдиним недоліком такого закону вважається його математична складність, що стримує його застосування для вирішення практичних задач. Державним стандартом України $[5,6]$ дифузійно-монотонний закон розподілу рекомендується застосовувати для механічних виробів, які складають значну частину виробів авіаційної техніки.

Виклад основного матеріалу дослідження.

Середні витрати на перебування виробу АТ у стані $h_{i}$ та на вихід зі стану дорівнюють [2]

$$
\mathrm{C}_{\mathrm{i}}(\mathrm{T})=\mathrm{C}_{\mathrm{ii}}(\mathrm{T}) \cdot \mu_{\mathrm{i}}(\mathrm{T})+\sum_{\mathrm{j}=1}^{7} \mathrm{P}_{\mathrm{ij}}(\mathrm{T}) \cdot \mathrm{C}_{\mathrm{ij}}(\mathrm{T}),
$$

де $\mathrm{C}_{\mathrm{ii}}(\mathrm{T})$ - витрати на перебування виробу AT в станах процесу технічної експлуатації, грн/год; $\mathrm{C}_{\mathrm{ij}}(\mathrm{T})$ - витрати на вихід виробу АТ з станів технічної експлуатації, грн.

В подальших розрахунках вважається, що $\mathrm{C}_{\mathrm{ii}}(\mathrm{T})$ представляє собою величину закупівельної вартості виробу АТ поділеної на призначений термін експлуатації, наприклад 20 років.

Питомі витрати на одиницю часу роботи виробу АТ дорівнюють 


$$
\mathrm{C}_{\text {ПИт }}=\frac{\sum_{\mathrm{i}=1}^{7} \mathrm{C}_{\mathrm{i}}(\mathrm{T}) \cdot \pi_{\mathrm{i}}(\mathrm{T})}{\pi_{\mathrm{i}}(\mathrm{T}) \cdot \eta_{\mathrm{i}}(\mathrm{T})},
$$

де $\pi_{\mathrm{i}}(\mathrm{T})$ - середня частота потрапляння марковського ланцюга до стану $h_{i}$;

$\eta_{\mathrm{i}}(\mathrm{T})$ - середня тривалість перебування виробу у будь-якому стані $h_{i}$;

$\mathrm{C}_{\mathrm{i}}(\mathrm{T})$ - середні витрати на перебування та вихід виробу зі стану $h_{i}$.

Будемо вважати, що закупівельна вартість виробу АТ дорівнює 193665 грн. Виріб, наприклад, працює 30 років. Тоді

$$
\mathrm{C}_{\mathrm{ii}}=\frac{193665}{8760 \cdot 30}=0,7369 \text { грн/год. }
$$

Витрати на технічну експлуатацію виробу АТ позначимо у матричній формі

$$
\mathrm{C}=\left(\begin{array}{ccccccc}
0,7369 & 0 & 0 & 0 & 0 & 0 & 0 \\
197927,7369 & 0 & 0 & 0 & 0 & 0 \\
0 & 0 & 0,736919792 & 0 & 0 & 1979 \\
65973 & 0 & 0 & 07369 & 0 & 0 & 0 \\
0 & 0 & 0 & 6593 & 07369 & 0 & 659,3 \\
6593 & 0 & 0 & 6593 & 0 & 0,7369 & 0 \\
0 & 0 & 0 & 0 & 0 & 0 & 0736
\end{array}\right)
$$

У наведеній матриці по головній діагоналі елементи матриці мають розмірність грн/год, а решта елементів мають розмірність у гривнях. У матриці (3) елемент $\mathrm{C}_{21}=19792 \quad$ грн - вартість проведення планових регламентних робіт, а $\mathrm{C}_{41}=65973 \quad$ грн - вартість проведення аварійного ремонту, яка суттєво більша за вартість планового ремонту. Елементи $\mathrm{C}_{54}=\mathrm{C}_{57}=\mathrm{C}_{61}=\mathrm{C}_{64}=6597,3$ грн - вартість контрольних операцій виробу АТ.

Результат розрахунків за формулою (4) покажемо у векторній формі $\mathrm{C}=(70 ; 19796$; 19793; 65980; 6598; 6598; 47) грн.

Наступним кроком здійснимо розрахунок витрат на одиницю календарного часу за формулою (2). $\quad \mathrm{C}_{\text {Пит }}=225 \quad$ грн/год. Тобто вартість однієї години роботи виробу АТ складає 225 грн.

$$
\left\{\begin{array}{l}
\mathrm{C}_{1}=\mathrm{C}_{11} \eta_{1}+\mathrm{P}_{12} \mathrm{C}_{12}+\mathrm{P}_{13} \mathrm{C}_{13}+\mathrm{P}_{15} \mathrm{C}_{15}+\mathrm{P}_{16} \mathrm{C}_{16} \\
\mathrm{C}_{2}=\mathrm{C}_{22} \eta_{2}+\mathrm{P}_{21} \mathrm{C}_{21} \\
\mathrm{C}_{3}=\mathrm{C}_{33} \eta_{3}+\mathrm{P}_{34} \mathrm{C}_{34}+\mathrm{P}_{37} \mathrm{C}_{37} \\
\mathrm{C}_{4}=\mathrm{C}_{44} \eta_{4}+\mathrm{P}_{41} \mathrm{C}_{41} \\
\mathrm{C}_{5}=\mathrm{C}_{55} \eta_{5}+\mathrm{P}_{54} \mathrm{C}_{54}+\mathrm{P}_{57} \mathrm{C}_{57} \\
\mathrm{C}_{6}=\mathrm{C}_{66} \eta_{6}+\mathrm{P}_{61} \mathrm{C}_{61}+\mathrm{P}_{64} \mathrm{C}_{64} \\
\mathrm{C}_{7}=\mathrm{C}_{77} \eta_{7}+\mathrm{P}_{73} \mathrm{C}_{73}+\mathrm{P}_{75} \mathrm{C}_{75}
\end{array}\right.
$$

Далі виконаємо розрахунок $C_{\text {lnum }}$ перебування виробу АТ у справному стані за формулою

$$
\mathrm{C}_{1 \text { пит }}=\frac{\mathrm{C}_{\text {пит }}(\mathrm{T}) \cdot \eta_{\text {сер }}(\mathrm{T})}{\mathrm{P}_{1}(\mathrm{~T}) \cdot \omega_{1}(\mathrm{~T})} \text {. }
$$

Для досліджуваного зразка АТ це значення складає 243 грн/год.

Чисельні значення $\mathrm{C}_{\text {пит }}$ та $\mathrm{C}_{1 п и т ~}$ отримані за умови, що регламентні роботи на виробах АТ проводяться $з$ періодичністю $\mathrm{T}=100$ год.

Організаторів експлуатації цікавить, як

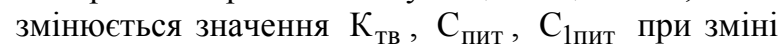
періодичності проведення регламентних робіт, а також при зміні інших параметрів експлуатації АТ.

Для оцінки техніко-економічної ефективності виробу АТ потрібно знати коефіцієнт технічного використання $K_{m \varepsilon}$. Цей коефіцієнт для вказаної моделі визначений у роботі [1] і дорівнює

$$
\kappa_{\mathrm{TB}}=\frac{\sum_{\mathrm{i}=1}^{\mathrm{h}} \pi_{\mathrm{i}}(\mathrm{T}) \cdot \omega_{\mathrm{i}}(\mathrm{T})}{\sum_{\mathrm{i}=1}^{\mathrm{h}} \pi_{\mathrm{i}}(\mathrm{T}) \cdot \eta_{\mathrm{i}}(\mathrm{T})},
$$

де $\pi_{\mathrm{i}}(\mathrm{T})^{2}$ - середня частота повернення марковського ланцюга до стану $\mathrm{h}_{\mathrm{i}}$;

$\eta_{\mathrm{i}}(\mathrm{T})$ - середній час перебування виробу АТ в $i$ му стані;

$\omega_{\mathrm{i}}(\mathrm{T})$ - середній час перебування виробу АТ у справному стані.

В математичній моделі будемо вважати відомими такі початкові дані: інтенсивність надходження сигналів помилкових тривог $\lambda=10^{-3} 1 /$ год, інтенсивність проявлення пропущених відмов, що сталися у АТ $\lambda_{\Pi \mathrm{P}}=10^{-2}$ 1/год, період проведення регламентних робіт $T=$ 100 год, тривалість контролю зразка АТ наземними засобами контролю $\mathrm{t}_{\Pi}=1$ год, тривалість контролю зразка АТ вбудованими засобами контролю $\mathrm{t}_{\Pi}^{*}=0,5$ год, тривалість виконання профілактичних робіт в наземних умовах $t_{\mathrm{P}}=5$ год, тривалість відновлення АТ у разі ії відмови $\mathrm{t}_{\mathrm{B}}=10$ год, достовірність контролю виробів АТ наземними засобами $\mathrm{d}_{\mathrm{H \Gamma}}=0,8$, достовірність контролю виробів АТ бортовими засобами $\mathrm{d}_{\mathrm{H \Gamma}}^{*}=0,55$, достовірність правильного визначення справного стану виробу АT $\mathrm{d}_{\Gamma}=0,7$, імовірність надходження сигналу про відмову виробів АТ від вбудованої системи контролю $\rho=$ 0,7 .

За формулами (5) і (6) виконані розрахунки $\mathrm{K}_{\text {тв }}$ i $\mathrm{C}_{1 п и т}$. Результати розрахунків наведені на рис.1-4. По вісі ординат ліворуч відкладені значення $\mathrm{K}_{\mathrm{TB}}$, а праворуч $-\mathrm{C}_{1 \text { пит }}$. По вісі абсцис на рис.1 відкладені значення періодичності проведення регламентних робіт $T$, на рис.2 достовірність контролю ОК наземними засобами контролю $\mathrm{d}_{\mathrm{H \Gamma}}$, на рис.3 - тривалість відновлення $t_{b}$, на рис.4 - тривалість контролю ОК наземними засобами контролю $\mathrm{t}_{\Pi}$.

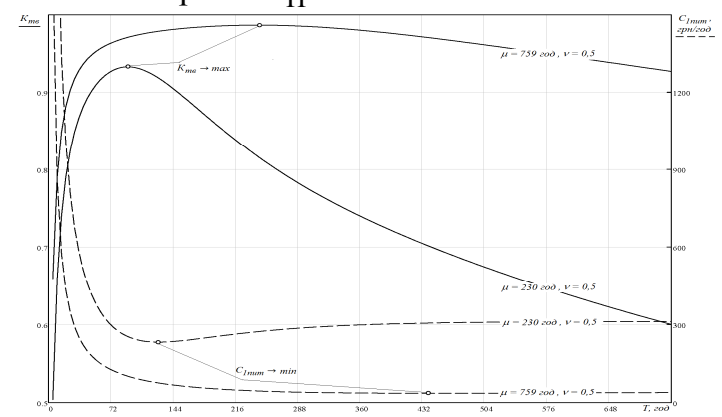

Рис.1. Залежність $\mathrm{K}_{\mathrm{тв}}$ i $\mathrm{C}_{1 п и т}$ від періодичності проведення регламентних робіт $\mathrm{T}$ 
Всі розрахунки виконані при постійних значеннях параметрів, що викладені вище, крім тих, що змінюються по вісі абсцис.

3 рис.1 видно, що існує оптимальний період проведення регламентних робіт, при якому забезпечується максимальне значення $\mathrm{K}_{\text {тв }}$.

При цьому існує мінімальне значення $\mathrm{C}_{1 \text { пит }}$, яке забезпечується при періодичності проведення регламентних робіт $T$, близької до оптимальної за критерієм $\mathrm{K}_{\mathrm{TB}} \rightarrow \max$.

Отримані результати мають велике практичне значення. Адже вибір періодичності проведення регламентних робіт не пов'язаний 3 додатковими витратами. Дотримання оптимальної періодичності проведення регламентних робіт $T$ може забезпечити не тільки максимальне значення $\mathrm{K}_{\mathrm{TB}}$, a $\mathrm{i}$ мінімальні питомі витрати на одиницю часу перебування виробу АТ у справному стані $\mathrm{C}_{1 \text { пит }}$.

Якщо відомий час використання виробу АТ, то можна визначити загальну вартість його експлуатації. 3 pис.1 видно, що $\mathrm{C}_{1 п и т ~} \cong 225$ грн/год. Отже при роботі виробу протягом 10 годин витрати на його експлуатацію складають $\mathrm{C}=225 \cdot 10=2250$ грн. Це забезпечить значення $\mathrm{K}_{\mathrm{TB}}=0,93$ при проведенні регламентних робіт через 108 годин. Отримані результати дають можливість організаторам експлуатації авіаційної техніки планувати проведення регламентних робіт i визначити очікувану вартість експлуатації виробу протягом певного часу.

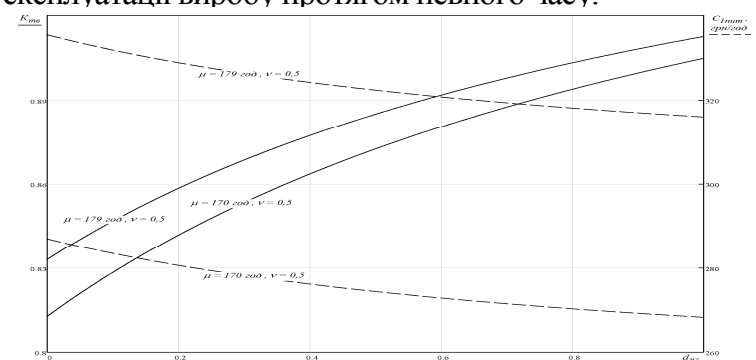

Рис.2. Залежність $\mathrm{K}_{\text {тв }}$ i $\mathrm{C}_{1 п и т ~}$ від достовірності засобів наземного контролю $\mathrm{d}_{\mathrm{Hг}}$

3 рис. 2. видно, що зі збільшенням достовірності наземних засобів контролю $\mathrm{d}_{\mathrm{Hг}}$ значно збільшується $\mathrm{K}_{\mathrm{TB}}$, а питомі витрати $\mathrm{C}_{1 \text { пит }}$ на годину перебування виробу АТ у справному стані повільно знижуються.

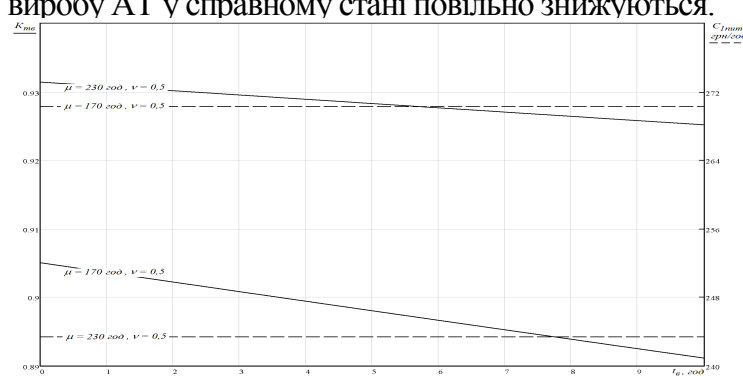

Рис.3. Залежність $\mathrm{K}_{\text {тв }}$ i $\mathrm{C}_{1 п и т}$ від тривалості відновлення $t_{b}$ виробів АТ

3 рис.3 видно, що зі збільшенням тривалості відновлення $\mathrm{K}_{\mathrm{Tв}}$ зменшується, а $\mathrm{C}_{1 п и т}$ від тривалості

\section{Література}

1. Яблонский П.М. Экономико - математическая модель технического обслуживания образцов вооружения и военной техники по состоянию для диффузионно - немонотонного відновлення $t_{\text {в }}$ практично не залежать при прийнятих початкових умовах.

3 рис.4 видно, що збільшення тривалості контролю наземними засобами $t_{\Pi}$ призводить до зменшення

$\mathrm{K}_{\text {тв }}$ за лінійним законом, а питомі витрати майже не змінюються при прийнятих початкових умовах

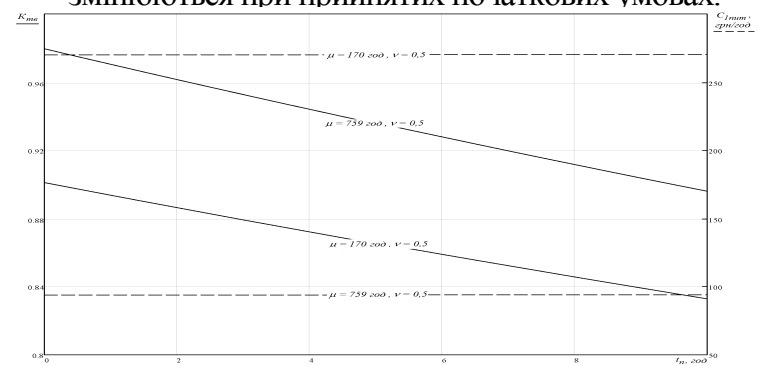

Рис.4. Залежність $\mathrm{K}_{\mathrm{тв}}$ та $\mathrm{C}_{1 п и т}$ від тривалості контролю наземними засобами контролю $\mathrm{t}_{\Pi}$

\section{Висновки й перспективи подалыших досліджень.}

У статті розроблена методика техніко-економічної оцінки ефективності експлуатації виробів АТ за станом для моделі дифузійно-монотонного закону розподілу часу їх відмов при врахуванні помилок першого i другого роду.

Показані залежності коефіцієнта технічного використання i питомих витрат на одиницю часу перебування виробу у справному стані від періодичності проведення регламентних робіт, достовірності контролю, тривалості відновлення i тривалості виконання профілактичних робіт для типових умов експлуатації.

Встановлено оптимальний період проведення регламентних робіт, при якому забезпечується максимальне значення коефіцієнта технічного використання і мінімальне значення питомих витрат на одиницю часу перебування виробу у справному стані.

Процеси, що відбуваються у запропонованій моделі, описуються за допомогою напівмарковського випадкового процесу у його класичному трактуванні.

Враховуючи наявність у моделі семи станів і складність дифузійно-монотонного розподілу відносно інших законів розподілу, основні розрахунки у статті здійснено чисельним методом, який при застосуванні сучасної обчислювальної техніки забезпечує досить високу точність обчислень.

Отримані у роботі результати можуть бути використані організаторами експлуатації АТ при обгрунтуванні параметрів, при яких досягаються найвищі показники технічної ефективності виробів 3 урахуванням вартості їх роботи.

Розроблена методика оцінки техніко-економічної ефективності експлуатації може бути застосована і до інших зразків техніки, в яких $є$ вбудовані засоби контролю, що постійно 3 певною ймовірністю контролюють основні параметри техніки, а також існують регламентні роботи, що проводяться з певною періодичністю.

распределения отказов / Яблонский П.М., Пустовой С.А., Опенько П.В.. Экономика и предпринимательство. - №8, 2013. С.436 - 443. 2. Мірненко В.I. Оцінка ефективності експлуатації 
за станом виробів авіаційної техніки для дифузійномонотонного розподілу їх відмов /Мірненко В.І., Пустовий C.O., Яблонський П.М. / Journal of Scientific Papers "Social development \& Security” - №1, 2017. - C. 58 - 68. 3. Volodymyr I Mirnenko The reliability measures computation of the series connected and reserved elements without recovery for diffusion-nonmonotonic distribution of their failures / Volodymyr I Mirnenko, Serhii O Pustovyi, Petro M Yablonskyi / Modern Information Technologies in the Sphere of Security and Defence. - № 1(22), 2015. - P. 83-89. 4. Volodymyr I Mirnenko Comparison of aerotechnics devise maintenance efficiency which are exploited with the technical condition for diffusion-monotonic and diffusion-nonmonotonic failure / Volodymyr I Mirnenko, Serhii O Pustovyi, Petro M Yablonskyi, Oleksandr V Avramenko / Modern Information Technologies in the Sphere of Security and Defence. - № 2(23), 2015. - Р. 88-93. 5. ДСТУ 3942-2000 (ГОСТ 27.506-2000). Надійність техніки. Плани випробувань для контролю середнього наробітку до відмови (на відмову). Частина 2. Дифузійний розподіл, 2001. - 36 с. 6. ДСТУ 2862-94. Надійність техніки. Методи розрахунків показників надійності. Загальні вимоги. $-1996 .-39$ c.

\title{
ТЕХНИКО-ЕКОНОМИЧЕСКАЯ ЕФЕКТИВНОСТЬ ЭКСПЛУАТАЦИИ ПО СОСТОЯНИЮ ИЗДЕЛИЙ АВИАЦИОННОЙ ТЕХНИКИ ДЛЯ ДИФФУЗИОННО-МОНОТОННОГО РАСПРЕДЕЛЕНИЯ ИХ ОТКАЗОВ
}

\author{
Владимир Иванович Мирненко (доктор техн. наук, профессор) \\ Анатолий Григорьевич Салий (канд.воен.наук, доцент) \\ Петр Михайлович Яблонский (канд. техн. наук, доцент) \\ Николай Пилипович Бутенко
}

\section{Национальный университет обороны Украины имени Ивана Черняховского, Киев, Украина}

В статье представлена методика оценки технико-экономической эффективности эксплуатации авиационной техники по состоянию с использованием диффузионно-монотонного распределения ее отказов с учетом ошибок первого и второго рода. Для типичных условий эксплуатации показаны графики зависимости коэффиииента технического использования и удельных затрат на час работы изделия авиационной техники в исправном состоянии от основных параметров. Описание процессов эксплуатации по состоянию изделий авиационной техники осуществляеся с помошью полумарковского случайного процесса, который, в отличие от марковского процесса, позволяет более адекватно описать эксплуатацию изделий авиационной техники.

Ключевые слова: технико-экономическая эффективность эксплуатации, коэффициент технического использования, диффузионно-монотонный распределение.

\section{THE FEASIBILITY STUDY OF CONDITION-BASED MAINTENANCE OF AERIAL VEHICUL WITH DIFFUSIVE-MONOTONOUS DISTRIBUTION OF THEIR FAILURES}

\author{
Volodymyr I. Mirnenko, (Doctor of Technical Sciences, Professor) \\ Anatolii G. Salii (Ph.D, Docent) \\ Petro M. Yablonskyi (Ph.D, Docent) \\ Mykola P. Butenko
}

The article represents the estimation methodology of condition-based maintenance of aerial vehicul feasibility study taking into account alpha and beta errors. The dependence charts of operating efficiency and vehicle operating costs per hour of work in good condition from the basic parameters of exploitation model for typical operating conditions are shown.

Keywords: maintenance, operating efficiency, diffusive-monotonous distribution, maintenance frequency.

\section{References}

1. Yablonskiy P.M. Ekonomiko - matematicheskaya model tehnicheskogo obsluzhivaniya obraztsov vooruzheniya i voennoy tehniki po sostoyaniyu dlya diffuzionno - nemonotonnogo raspredeleniya otkazov / Yablonskiy P.M., Pustovoy S.A., Openko P.V.. Ekonomika i predprinimatelstvo. - \#8, 2013. - S.436-443. 2. Mirnenko V.I. Otsinka efektyvnosti ekspluatatsii za stanom vyrobiv aviatsiinoi tekhniky dlia dyfuziino-monotonnoho rozpodilu yikh vidmov /Mirnenko V.I., Pustovyi S.O., Yablonskyi P.M. / Journal of Scientific Papers "Social development \& Security" №1, 2017. - S. 58 - 68. 3. Volodymyr I Mirnenko The reliability measures computation of the series connected and reserved elements without recovery for diffusion-nonmonotonic distribution of their failures / Volodymyr I Mirnenko, Serhii O Pustovyi, Petro
M Yablonskyi / Modern Information Technologies in the Sphere of Security and Defence. - № 1(22), 2015. - P. 83-89. 4. Volodymyr I Mirnenko Comparison of aerotechnics devise maintenance efficiency which are exploited with the technical condition for diffusion-monotonic and diffusion-nonmonotonic failure / Volodymyr I Mirnenko, Serhii O Pustovyi, Petro M Yablonskyi, Oleksandr V Avramenko / Modern Information Technologies in the Sphere of Security and Defence. - № 2(23), 2015. - P. 88-93. V.V. i dr. Pod redaktsiey I.A.Ushakova - M.: Radio i svyaz, 1985. - 609 p. 5. DSTU 3942-2000 (GOST 27.506-2000). Nadiynist tehniki. Plani viprobuvan dlya kontrolyu serednogo narobItku do vIdmovi (na vIdmovu). Chastina 2. Difuziyniy rozpodil, 2001. - 36 p. 6. DSTU 2862-94. Nadiynist tehniki. Metodi rozrahunkiv pokaznikiv nadiynostI. Zagalni vimogi. - 1996. - 39 p. 